\title{
A humanização da criança na educação infantil: implicações da teoria histórico-cultural
}

Humanization of the child in early childhood education: implications of the theory of cultural history

\author{
Dayanne Vicentini* \\ Universidade Estadual de Londrina
}

Marta Silene Ferreira Barros**

Universidade Estadual de Londrina

Resumo O presente estudo tem como objetivo discutir o processo de humanização da criança na educação infantil a partir da concepção dos professores, sob a perspectiva materialista dialética e Histórico-Cultural. Procuramos responder a seguinte indagação: qual é o papel da escola infantil no processo de humanização da criança? Via de regra, as instituições de ensino infantil inseridas no contexto capitalista, acabam por perpetuar ideologias conservadoras, formando o indivíduo unilateral a serviço do mercado de trabalho. Para a realização da pesquisa, utilizamos o questionário como instrumento de coleta de dados, a fim de conhecer a concepção do professor sobre o papel da escola na humanização das crianças. Diante disso, acredita-se que a formação omnilateral da criança pequena, suas experiências e interação com o outro ao longo do seu processo de desenvolvimento, possibilitará o acesso ao conhecimento elaborado e à apropriação das máximas qualidades humanas.

PALAVRAS-CHAVE: Educação infantil; Desenvolvimento; Humanização.

Abstract This study aims to discuss the child's humanization process in early childhood education from the design of teachers, under the dialectical materialist perspective and historical-cultural. We seek to answer the following question: what is the role of kindergarten in child humanization process? As a rule the children's educational institutions entered the capitalist context end up perpetuating conservative ideologies for$\mathrm{ms}$ the unilateral individual in the service of the labor market. For the research, we use the questionnaire as a data collection instrument in order to know the design of the teacher about the school's role in the humanization of children. Therefore, it is believed that the omnilateral training young child will enable access to improved knowledge and appropriation of the highest human qualities.

KEYWORDS: Childhood education; Development; Humanization. 


\section{Introdução}

Nas últimas décadas, importantes debates na área educacional se ocupam nos estudos por questões relacionadas à instituição "escola": Que espaço é este? Que tipo de homem deve-se formar? Inúmeras são as concepções que cercam essas problemáticas com o intuito de resolvê-las, fundamentadas por determinadas vertentes epistemológicas.

Com o intuito de responder às questões acima expostas, a pesquisa tem como objetivo analisar o papel da escola infantil sob a perspectiva Materialista Dialética e Histórico-Cultural, cujo foco é o desenvolvimento humano. O estudo é resultado dos projetos de pesquisa "Formação e Ação Docente: implicações e possibilidades do marxismo e da Teoria Histórico-Cultural para o desenvolvimento humano" e "FOCO - Formação Continuada: implicações do Materialismo Histórico e Dialético e da Teoria Histórico-Cultural na prática docente e no desenvolvimento humano", vinculados ao programa de Pós Graduação da Universidade Estadual de Londrina.

Concebendo o ser humano como um ser que desde o seu nascimento entra em contato com o mundo, a visão materialista dialética de homem e sociedade, desenvolvida por Karl Marx, está centrada na concepção de que o ser humano produz sua própria história. Ele é seu próprio criador na interação que estabelece com os outros sujeitos e dá à luz a si mesmo no percurso da história. O principal fator dessa autocriação da raça humana está em sua relação com a natureza e, por conseguinte, consigo mesmo (FROMM, 1962).

É por meio do trabalho que o homem transforma a natureza, e ao transformá-la nos meios de produção - matérias primas, fonte de energia, etc. - e nos meios de subsistência - comida, casa, roupa, etc. - produz novas necessidades e possibilidades. Tais aspectos impulsionam o desenvolvimento tanto do indivíduo quanto da sociedade. Neste sentido, a história da humanidade é o processo de desenvolvimento da sociedade e dos indivíduos que a compõem (LESSA; TONET, 2012).

Desse modo, o movimento da história só é possível com a transmissão às novas gerações das aquisições da cultura humana, ou seja, a educação. Quanto mais a humanidade progride, mais rica será a prática sócio-histórica acumulada por ela; maior será, portanto, o crescimento do papel específico da educação e, com isso, mais complexa sua tarefa. (LEONTIEV, 1978).

Concebendo a educação como fenômeno particularmente humano, podemos analisá-la dialeticamente e pensar em um ato educativo que possibilite o desenvolvimento dos homens a partir da apropriação da cultura historicamente elaborada, tendo o adulto como principal mediador desse processo. Em se tratando da escola infantil, é necessário que toda a equipe pedagógica receba uma formação de qualidade, que proporcione aos professores reflexões sobre sua práxis, de modo que ocorra o processo de ensino e aprendizagem e, consequentemente, o desenvolvimento das crianças. Com efeito, o trabalho deve pautar-se em uma prática pedagógica planejada, considerando que o espaço da escola infantil é o lugar privilegiado para a educação da criança pequena, pois é nele que a criança vivencia momentos de interação com outras crianças e com o adulto - professor. 
A partir destes princípios, dividimos o trabalho em três momentos. No primeiro, faremos uma breve consideração acerca do papel da escola infantil no contexto do sistema social capitalista e suas implicações para o desenvolvimento infantil. Em seguida, discutiremos o papel da escola da infância no processo de humanização da criança a partir da perspectiva Histórico-Cultural e a interação como um fator que favorece o desenvolvimento da criança. Por fim, será realizada uma análise das falas de professores atuantes na escola infantil, dando ênfase à sua concepção acerca do papel da instituição de ensino infantil para a humanização das crianças pequenas.

Acreditamos que a pesquisa poderá contribuir para incitar debates, em âmbito acadêmico, relacionados à temática posta em questão e ampliar os horizontes para professores no que diz respeito à intencionalidade de seu trabalho pedagógico nas escolas da infância, para que contribuam para o desenvolvimento integral das crianças e sua humanização.

\section{O papel da escola no contexto capitalista}

O homem é um ser naturalmente social, o que significa dizer que suas capacidades ontológicas - habilidades, aptidões, ou seja, inteligência e personalidade - são aprendidas. Os estudos desenvolvidos na Teoria Histórico-Cultural por Vigotsky ${ }^{1} \mathrm{e}$ seus colaboradores ressaltam que a "essência do processo de desenvolvimento é a apropriação da experiência acumulada historicamente, pois a fonte das qualidades humanas é a cultura" (MELLO; LUGLE, 2014). Em outras palavras, a aprendizagem da cultura elaborada é a condição para que o desenvolvimento humano ocorra.

Marx (1962) contrapôs muitos sociólogos e psicólogos contemporâneos que afirmavam que natureza do homem ao nascer era como uma folha em branco na qual a cultura escrevia seu texto. Sua ideia partia do princípio de que

[...] o homem como homem é uma entidade identificável e verificável, podendo ser definido como homem não apenas biológica, anatômica e fisiologicamente, mas também psicologicamente (FROMM, 1962, p. 34, grifo no original).

O ser humano se torna humano à medida que atua sobre a realidade, apropria-se dos elementos da cultura e da natureza, transformando-as e transformando a si mesmo por intermédio do trabalho. Marx em estudos acerca da natureza ontológica do homem coloca em questão a diferença entre o homem e o animal. Diferentemente dos animais, o homem tem a capacidade de transformar a natureza para si, já o animal se adapta a ela.

Nas palavras de Marx e Engels (1984, p.27), a distinção entre o homem e o animal pode ser percebida "pela consciência, pela religião ou por tudo que se queira. Mas eles próprios começam a se diferenciar dos animais tão logo começam a produzir seus meios de vida".

Leontiev (1978) esclarece que o desenvolvimento humano acontece a partir da relação entre o homem e a cultura, pois cada geração inicia sua vida no mundo de objetos e fenômenos criados pelas gerações anteriores. Na medida em que o homem 
participa do trabalho e das inúmeras formas de atividade social, apropria-se das riquezas deste mundo, desenvolvendo, assim, aptidões especificamente humanas.

É mister assinalar que o desenvolvimento do ser humano é resultado de um processo histórico-social: ao desempenhar suas atividades por meio do trabalho, ele estará ao mesmo tempo produzindo e se apropriando da cultura.

Ainda para Leontiev (1978), as relações do indivíduo com o mundo têm sempre como intermediário a relação do homem com os outros homens, sua atividade está inserida na comunicação - quer se efetue sob a forma exterior, sob a forma inicial de atividade em comum ou até mesmo sob a forma de comunicação verbal ou mental, sendo condição específica e indispensável para o desenvolvimento humano na sociedade.

Conforme o homem aprende a utilizar os objetos da cultura (materiais ou não materiais; instrumentos e signos), vai reunindo experiências em comunicação com outros homens, exercitando a percepção, se apropriando da linguagem, constituindo memória, internalizando formas de pensar, criando condições para controlar sua própria conduta. Tais aspectos possibilitarão o desenvolvimento de sua inteligência e personalidade (MELLO; LUGLE, 2014).

Neste sentido, pode-se considerar a escola como um dos espaços promotores desse desenvolvimento. Mas, como isso pode acontecer?

De acordo com Marsiglia (2011), a escola configura-se como uma instituição social que tem como papel primordial o acesso ao conhecimento sistematizado daquilo que a humanidade já produziu. Esse conhecimento torna-se necessário às novas gerações, pois possibilita o avanço a partir do que já foi construído historicamente.

Diferentes visões sobre escolas são encontradas em diferentes teorias educacionais e em cada uma delas, consequentemente, é possível reconhecer se elas contribuem para o status quo da sociedade, isto é, para a manutenção do sistema econômico capitalista, ou para sua transformação, buscando a humanização dos indivíduos. Isso irá depender da participação de alunos, pais e professores na escola, da maneira com que os conteúdos são escolhidos, como são discutidos, apresentados, planejados e ensinados (MARSIGLIA, 2011).

$\mathrm{Na}$ concepção marxista, a educação e o ensino são determinados, em última instância, pelo modo de produção da vida material, isto é, pela forma com que os homens produzem a vida material, bem como as relações aí implicadas por meio do trabalho (LOMBARDI, 2012). O aparato escolar, inserido em um contexto social capitalista, acaba por perpetuar a ideologia presente na ordem estabelecida, ou seja, nos modos e nas relações de produção. Para Marx e Engels (2004), o sistema de ensino pode ser compreendido como uma qualificação da força de trabalho em sua concretude, que alcançará o seu máximo aproveitamento se conseguir a adaptação e a integração dos indivíduos ao sistema capital. Esta seria a única maneira de não desperdiçar a sua força de trabalho, e sim aproveitá-la. Em suma, o ensino reproduz o sistema dominante "tanto a nível ideológico quanto técnico e produtivo" (MARX; ENGELS, 2004, p.15). 
Embora as análises de Marx e Engels acerca dos moldes educacionais tenham ocorrido no contexto do século XIX, podemos perceber que suas ideias permanecem atuais. Martins (2004, p. 53) evidencia que cada vez mais o processo educacional está "atrelado à construção de competências". Os diversos segmentos do âmbito da educação, que perpassam a educação infantil até o ensino superior, estão inseridos em políticas educacionais focadas no treinamento de indivíduos para atuar no mercado de trabalho. A crítica da autora recai sobre a redução da educação ao objetivar uma formação de competências, o que empobrece os fins educacionais, convertidos numa adaptação passiva do sujeito às exigências do sistema mercadológico.

Marx defendia uma formação omnilateral do ser como forma de superação do modelo de formação unilateral do homem, presente na sociedade capitalista. Segundo Netto e Lucena (2016), Marx e Engels lutavam por uma educação que fosse capaz de contemplar o homem em todas as suas dimensões, em sua integralidade. Manacorda (1996) esclarece que para Marx e Engels a omnilateralidade era entendida como a chegada histórica do homem à totalidade de capacidades produtivas e, concomitantemente, a uma totalidade de capacidades de consumo e prazeres, ao passo que se deve considerar acima de tudo o desfrute de bens materiais, do qual o trabalhador tem sido excluído por consequência da divisão social do trabalho.

Neste sentido, Frigotto assinala que, atualmente, para formar o sujeito por intermédio da perspectiva omnilateral, dentro de uma concepção de que as pessoas estão em primeiro lugar, pressupõe-se tornar senso comum a noção de que as relações capitalistas são, por sua própria natureza, incapazes de prover o conjunto de direitos fundamentais a todos; a iniciar pelo direito "à vida digna, à saúde, à educação, habitação, emprego ou salário desemprego, lazer, etc., sem o que o humano se atrofia" (FRIGOTTO, 1996, p. 157).

\section{O papel da escola infantil na humanização da criança pe- quena}

Se partirmos do pressuposto de que a aprendizagem impulsiona o desenvolvimento, então a criança aprende desde que nasce. A partir do início de sua vida, ela está inserida na "herança cultural da humanidade que é partilhada pelo grupo social do qual ela participa e que se faz presente no momento da história em que vive" (MELLO; FARIAS 2010, p.55). Esta herança cultural é repleta de saberes, hábitos, costumes, objetos, formas de pensar, linguagens, etc., as quais fazem parte da cultura elaborada pelas gerações anteriores (MELLO; LUGLE, 2014).

Mas, qual é o lugar por excelência que, organizado intencionalmente, possibilita a apropriação das máximas qualidades humanas? Mello (2007b) assevera que a creche e a escola da infância podem e devem ser o melhor espaço para a educação das crianças. Nelas torna-se possível garantir o acesso dos pequenos às qualidades humanas, que, externas ao indivíduo no nascimento, precisam ser apropriadas pelas novas gerações por meio de atividades vividas coletivamente.

A Teoria Histórico-Cultural, diferentemente das teorias que tratam a humanização como algo metafísico ou como produto da herança genética, enxerga o homem e sua humanidade como produto da sua atividade social, criada pelo próprio 
ser humano ao longo da história da humanidade. Ao criar a cultura humana - objetos, instrumentos, valores, hábitos e costumes, criamos a nossa humanidade, isto é, "o conjunto das características e das qualidades humanas expressas pelas habilidades, capacidades e aptidões que foram se formando ao longo da história por meio da própria atividade humana" (MELLO, 2007b, p.86). Para Marx (1962), todas as relações que o homem estabelece com o mundo, como ver, ouvir, saborear, desejar, pensar, agir, enfim, todos os órgãos da sua individualidade são sua ação objetiva para se apropriar da realidade humana.

É compromisso do processo educacional organizar de modo intencional as condições adequadas para possibilitar a máxima apropriação das qualidades humanas. Mas, para que isso aconteça é imprescindível conhecer quais são as condições apropriadas para a aprendizagem da criança. Kramer (2003) assinala que a creche e a pré-escola precisam ser pensadas como instâncias de formação cultural e as crianças, como sujeitos de cultura e história, como sujeitos sociais.

Conceber a escola da infância como instituição provedora da humanização da criança requer conhecer os períodos do desenvolvimento psíquico individual de cada faixa etária. Compreendendo cada um deles, o professor terá um aporte teórico acerca da Teoria Histórico-Cultural para um trabalho pedagógico intencional e de qualidade, possibilitando o desenvolvimento da atividade principal em cada período. E por meio das atividades principais que a criança relaciona-se com o mundo e, em cada estágio, criam-se necessidades específicas em termos psíquicos (FACCI, 2004).

Vale salientar que os principais estágios do desenvolvimento pelos quais os indivíduos passam caracterizam-se por: comunicação emocional direta do bebê, atividade objetal manipulatória, jogo de papéis, atividade de estudo, comunicação íntima pessoal e atividade profissional/estudo ${ }^{2}$.

A comunicação emocional direta do bebê estende-se desde as primeiras semanas de vida do bebê até a idade de mais ou menos um ano, configurando-se como "base para a formação de ações sensório-motoras de manipulação" (FACCI, 2004.p.67). Já o segundo período compreende a atividade objetal manipulatória, quando acontece a assimilação de procedimentos socialmente elaborados de ação com os objetos. Para que aconteça essa assimilação é necessário que os adultos mais experientes apresentem essas ações para as crianças. Por intermédio da linguagem, a criança mantém contato com o adulto e vai aprendendo a manipular os objetos criados pelos homens (FACCI, 2004).

O terceiro estágio de desenvolvimento da criança compreende a idade pré - escolar e tem o jogo de papéis como atividade principal. Nesta fase, a criança apropria-se do mundo concreto dos objetos humanos por meio da "reprodução das ações realizadas pelos adultos com esses objetos" (FACCI, 2004.p.69). Facci evidencia que as brincadeiras das crianças não são instintivas e a percepção que a criança tem do mundo e dos objetos do homem determinam seu conteúdo. A autora afirma ainda que "a criança opera com os objetos que são utilizados pelos adultos e, dessa forma, toma consciência deles e das ações humanas realizadas com eles". 
É necessário que cada estágio do desenvolvimento infantil, seja respeitado e trabalhado pelo professor mediador, evitando que sofram rupturas que ocasionariam atrasos em seu processo de aprendizagem.

\section{Interação e experiência no processo de desenvolvimento infantil}

$\mathrm{Na}$ concepção Histórico-Cultural, o desenvolvimento do indivíduo está intimamente relacionado com sua relação com o outro, ou seja, na interação que se estabelece entre os sujeitos, nas atividades, nas experiências e vivências sociais, o homem se humaniza e elabora sua própria existência.

De acordo com a teoria, o desenvolvimento da inteligência do homem, da personalidade, das emoções, da consciência e do relacionamento com as outras pessoas acontece na vida do sujeito por meio da atividade infantil, a partir das condições de vida, dos processos de educação e interação social. Portanto, o desenvolvimento cultural "constitui-se na atividade humana mediada pelas relações e pelas objetivações humanas, social e historicamente produzidas" (SILVA, 2015, p.77). Isso significa afirmar que a natureza humana é social, pois o homem torna-se verdadeiramente homem durante as experiências que adquire no meio em que vive. Ele não nasce acabado: as características humanas são extrínsecas a ele no nascimento. Destarte, ele se humaniza por intermédio das vivências em sociedade, da educação e interação com o outro. Apropriando-se da experiência social, ele a transforma em sua própria experiência individual.

Considerando tal assertiva, Mello e Teixeira (2012) assinalam que a compreensão acerca do desenvolvimento humano não pode ser justificada somente por fatores biológicos. $\mathrm{O}$ desenvolvimento ocorre a partir de inúmeros elementos e ações que se estabelecem ao longo da vida do indivíduo. Neste processo, pode-se afirmar que a interação com outras pessoas desempenha um papel primordial na formação humana.

É na educação infantil que a criança adquire suas primeiras vivências e experiências, tanto no contexto familiar, como fora dele. $\mathrm{Na}$ escola, por exemplo, a criança interage com outras e com os adultos, entrando em contato com a cultura elaborada, e é neste processo que a interação em grupo se intensifica. A frequência de encontros torna a experiência diferenciada de qualquer outra vivenciada nessa fase inicial em que se imputa à escola o status de espaço legítimo de construção e partilha de conhecimentos. "Nela, a interação é constante, mesmo quando não mediadas pelo educador se consolidam aprendizagens que não constam nos currículos escolares" (MELLO, TEIXEIRA, 2012, p.04).

Nogueira (2016) sinaliza que ao adulto que educa cabe, pois, promover atividades que intencionalmente coloquem a criança em interação, para que a comunicação se configure como uma necessidade, promovendo, assim, o desenvolvimento. Sendo assim, avalia-se que o processo de interação social desde a infância não se desvincula da experiência da criança, que pode, no processo, se transformar em vivências. 
Assim, Corsino (2006) desataca que os estudos de Vigotsky apontam que o ser humano se constitui como tal na sua relação com o outro. Portanto, a interação social é um processo que acontece por meio de indivíduos com modos de agir determinados histórica e culturalmente, não sendo possível desintegrar as dimensões afetivas e cognitivas dessas interações, bem como as dimensões dos planos psíquico e fisiológico do desenvolvimento. Nos seus processos interativos, as crianças não somente recebem cultura, mas também a criam e transformam.

Suas ações são também forma de re-elaboração e recriação do mundo. Desde que nasce, o bebê reage ao entorno, ao mesmo tempo em que provoca reações naqueles com os quais se relaciona. As ações da criança são simultaneamente individuais e únicas (CORSINI, 2006, p. 06).

A partir disso, vale reforçar que, para se desenvolver, a criança necessita interagir com o outro. Vigotsky (1998) defende a relação entre a necessidade das crianças interagirem com o brincar para se desenvolver. Neste sentido, a promoção de atividades que proporcionem o envolvimento da criança em brincadeiras, principalmente aquelas que favorecem a criação de situações imaginárias, deve objetivar sua função pedagógica. A escola infantil pode se utilizar deliberadamente desse tipo de situação para atuar no processo do desenvolvimento das crianças (VIGOTSKY, 1998, p.67).

Segundo Moruzzi (2014, p. 21), "não é pouco pensar que a educação infantil é o espaço tempo de interação e brincadeira”. A interação neste sentido significa articular todas as linguagens que a criança pequena utiliza para se expressar e explorar cada uma delas ao máximo na relação com as outras crianças. Para a Teoria HistóricoCultural, a interação possui um papel fundamental no desenvolvimento da mente, pois a partir das interações criança-criança e criança-adulto são estabelecidos processos de aprendizagem e, por consequência, o aprimoramento das estruturas mentais existentes desde o nascimento (MELLO, TEIXEIRA, 2012).

Desse modo, a interação social, na Teoria Histórico-Cultural, desempenha um papel central para o desenvolvimento do indivíduo, já que este se apropria e produz cultura por intermédio das relações com outros indivíduos e o meio em que vive, possibilitando ao sujeito viver experiências no seu cotidiano, sejam nas instâncias formais ou informais. Nesse estudo, destaca-se a escola como lócus essencial onde o processo de interação e experiência ocorre, favorecendo o desenvolvimento infantil.

\section{O papel da escola infantil a partir do olhar de educadores}

Com o intuito de conhecer a concepção de professores acerca do papel da escola infantil, realizamos uma pesquisa com 8 professores, alunos da pós-graduação lato sensu - Trabalho Pedagógico na Educação Infantil, do Departamento de Educação da Universidade Estadual de Londrina, e atuantes na educação infantil. A questão norteadora que fora proposta preocupou-se em suprir a seguinte análise: qual o papel da educação infantil no processo de humanização da criança?

No primeiro momento, nosso objetivo é apresentar as respostas literais de cada entrevistado; em seguida, realizaremos uma discussão contemplando os aspectos principais que apareceram nas falas dos professores, a fim de analisarmos suas ideias ${ }^{3}$. 
Para o professor $A$, a escola infantil deve considerar a criança

[...] como um ser em formação, respeitando sua infância, não acelerando ou desprovendo a criança de sua etapa de vida, mas ao mesmo tempo sabendo desempenhar seu papel pedagógico em prol da aprendizagem e desenvolvimento da criança.

É necessário reconhecer a criança como um ser em formação e a prática pedagógica do professor precisa respeitar cada período do desenvolvimento infantil e sua atividade principal, que proporcionará o desenvolvimento integral da criança. $\mathrm{O}$ papel do professor, adulto mais experiente, pai, mãe, é o de possibilitar que na criança se formem, constantemente, novas necessidades humanizadoras (MELLO, 2007a).

O professor $B$ acredita que " $a E d$. Infantil tem o dever de apresentar o novo para as crianças ampliando o conbecimento de cada indivíduo". Além de apresentar o novo, o espaço da escola infantil é um espaço privilegiado para a interação com outras crianças e também com os adultos, o que possibilita o desenvolvimento e aprendizagem das crianças pequenas. Essas interações são importantes para o desenvolvimento em vários aspectos: "cognitivo, social, afetivo e físico" (PARANÁ, 2006, p.16).

O professor $C$ assinala que "o papel da escola infantil é de suma importância visto que educar e humanizar são intrinsecos e indissociáveis". De acordo com a Teoria Histórico-Cultural, o ato de humanizar já deve estar imbricado na própria educação das crianças. Deve-se considerar a humanização como um processo de educação, pois ao criar cultura humana -objetos, instrumentos, valores, hábitos e costumes, criamos humanidade, ou seja,

[...] o conjunto das características e das qualidades humanas expressas pelas habilidades, capacidades e aptidões que foram se formando ao longo da história por meio da própria atividade humana (MELLO, 2007b, p.86).

O professor $D$ diz que o papel da escola infantil

é o de oferecer subsídios coerentes de como o ser humano se torna humano em contato com outros de sua espécie se apropriando da cultura, dos costumes, das crenças, valores, tudo interligado ao processo educativo. Passando assim, saberes "humanizadores" construídos e acumulados historicamente com o intuito de repassá-los para as próximas gerações. E assim dando sequência a este processo.

Se o papel da escola infantil é o de transmitir saberes "humanizadores", o professor necessita constituir-se como o intelectual que planeja e cria na escola as situações de vida e educação que "possibilitem a internalização por cada criança das máximas qualidades humanas existentes na sociedade" (MELLO, 2007a, p.12). Organizar intencionalmente o processo educativo requer de nós, professores da infância, que nos ancoremos em concepções que fundamentem e orientem nossas decisões e escolhas.

Se acreditamos que o papel da escola infantil é o de contribuir significativamente para o desenvolvimento da criança, a Teoria Histórico-Cultural pode nos oferecer os subsídios necessários para uma prática educativa coerente, pois "não há prática sem teoria”. Isto é, apenas a apropriação de uma teoria permite liberdade e condições 
de analisarmos os problemas existentes na prática educativa, bem como compreendê-los em sua complexidade (MELLO, 2007a, p.13). Essa perspectiva enxerga o ser humano e sua humanidade como produtos da história criada pelos próprios homens ao longo do tempo (MELLO, 2007b).

O professor $E$ alega que

[...] a educação infantil possui grande importância no processo de humanização, pois através da educação infantil se tem uma educação intencional voltada para o desenvolvimento da criança para que ela aprenda de forma correta tudo o que precisa para seu desenvolvimento.

Tudo o que a criança precisa para seu desenvolvimento está na riqueza da cultura produzida pelos homens. É neste meio cultural que a criança pequena vive a experiência social e entra em contato, pela primeira vez, com as características propriamente humanas, que aos poucos serão internalizadas e se tornarão funções psíquicas. A partir disso, o meio se consolida como um elemento ativo no processo de formação das qualidades humanas em cada indivíduo. Os mediadores, aquelas pessoas mais experientes com quem a criança convive na relação com a cultura, também são ativos: "são eles que permitem que a criança se aproprie dos significados dos objetos da cultura que se abre cada vez mais para ela" (MELLO, 2007a, p.15).

À medida que ocorre esse movimento dialético em que as crianças convivem com os adultos mais experientes e aprendem a utilizar a cultura socialmente elaborada, acontece a apropriação das qualidades humanas criadas no decurso da história (MELLO, 2007a).

\section{O professor $F$ diz:}

O espaço da educação infantil é onde ocorre o maior processo de humanização com as crianças pequenas. As crianças saem do estado de conforto maternal, e vivenciam não só novas aprendizagens, mas também influenciam a maneira como novas experiências são conduzidas para as crianças pequenas, seja pelo adulto professor (a), seja por outra criança.

Saviani (2000) salienta que o objeto da educação está relacionado, de um lado, com a identificação dos elementos culturais que devem ser assimilados pelos sujeitos da espécie humana para que assim, se tornem humanos e, paralelamente, por outro lado, com a descoberta das formais mais viáveis para atingir esse objetivo. Assim, para que a humanização ocorra por meio da educação é imprescindível que os saberes elaborados sejam socializados e apropriados pelas gerações.

O professor $G$ expõe que

[...] a educação infantil vai envolver a criança em um processo intencional e sistematizado de humanização. É por meio de um adulto experiente, capacitado, que a criança vai adquirindo, ou melhor, tendo contato com a herança cultural produzida pela humanidade, e nesta experiência vai se humanizando. 
Sobre as aquisições das aptidões historicamente desenvolvidas, Leontiev (1978, p.272, grifo no original) afirma que estas não são simplesmente "dadas aos homens nos fenômenos objectivos da cultura material e espiritual que os encarnam, mas são aí apenas postas". Isso quer dizer que, para se apropriar dos resultados, ou seja, para fazer deles suas aptidões, a criança, o ser humano deve estabelecer uma relação com os fenômenos do mundo a sua volta por meio de outros homens, num processo de comunicação entre eles. Deste modo, "a criança aprende a actividade adequada. Pela sua função, este processo é, portanto, um processo de educação" (LEONTIEV, 1978, p.272, grifo no original).

Para o professor $H$,

[...] o papel da educação infantil para o processo de humanização da criança é fundamental, pois, o ensino é o principal meio de desenvolvimento da criança, por intermédio deste a criança irá se humanizar. Mediante a escola, as funções desse sujeito (criança) são desenvolvidas, apropriadas e elevadas para um nível superior na qual este se encontrava. Este é o papel principal da escola... humanizar a criança para que esta se desenvolva em suas funções, ou seja, tornese homem em suas qualidades humanas.

As entrevistas realizadas com os professores revelam que a maioria deles percebe o caráter humanizador da escola infantil. Em nenhuma fala está implícita que a escola possui a função de preparar a criança futuramente para o mercado de trabalho. Os entrevistados demonstram acreditar que a criança necessita estar na escola para desenvolver suas potencialidades enquanto ser humano, por meio de experiências e interação com o outro.

O trabalho educativo do professor desempenha um papel fundamental na vida das crianças. Ele, como mediador e propulsor de interações no espaço escolar, possibilita o desenvolvimento da criança pequena, contribuindo para suas constantes descobertas e aprendizagens no meio escolar. Para Saviani (2000), o trabalho educativo é o ato de produzir em cada indivíduo, direta e intencionalmente, a humanidade que é produzida tanto historicamente, quanto coletivamente pelos homens. Desse modo, o objeto da educação refere-se à identificação dos elementos da cultura que devem ser assimilados pelos sujeitos da "espécie humana para que eles se tornem humanos e, de outro lado e concomitantemente, à descoberta das formas mais adequadas para atingir esse objetivo" (SAVIANI, 2000, p.17).

Em suma, o professor é o responsável por a escola ser a força motriz no processo de apropriação do conhecimento e das máximas qualidades humanas pela criança, tornando-a um ser verdadeira e completamente humano.

\section{Considerações finais}

O papel da escola infantil a partir do Materialismo Histórico Dialético e da Teoria Histórico-Cultural nos auxilia a compreender este espaço como lugar privilegiado no desenvolvimento e aprendizagem da criança pequena, pois contribui para a sua humanização. 
Infelizmente, a maioria das escolas da infância inseridas no contexto capitalista atual acaba por perpetuar as ideologias presentes no sistema, preparando sujeitos desde sua tenra infância para servir ao mercado de trabalho, formando assim o homem unilateral.

Marx e Engels, apesar de não terem dedicado seus estudos especificamente à área educacional, contribuíram significativamente para repensarmos questões relacionadas ao ensino e formação dos sujeitos. Juntamente com a Teoria Histórico-Cultural, o Materialismo Dialético nos fornece os subsídios necessários para que possamos compreender melhor o processo de desenvolvimento humano, sua natureza específica, seu modo de subsistência e suas relações com a cultura e com outros homens.

Pudemos ver, ao longo da pesquisa, que a educação configura-se como um fenômeno educativo especificamente humano, e é por meio dela que os homens podem ter acesso à cultura historicamente elaborada por outros homens, apropriando-se das máximas qualidades humanas.

Cabe à escola infantil, enquanto o lugar mais importante para o desenvolvimento das crianças de 0 a 6 anos, desempenhar a função humanizadora, planejando um trabalho intencional, estabelecendo relações saudáveis entre as próprias crianças e os adultos, e possibilitando o acesso à cultura.

Para que escola concretize seu papel humanizador, é imprescindível apostar em cursos de formação continuada para os professores, que ofereçam momentos de estudo e reflexão sobre sua práxis pedagógica, a fim de provocar mudanças no trabalho docente possibilitando a aprendizagem e o desenvolvimento das crianças pequenas.

\section{Referências}

CORSINO, P. O cotidiano na educação infantil. 2006. Disponível em: <http://drb-assessoria. com.br/6ocotidianonaeducacoinfantil.pdf>. Acesso em: 20 out. 2016.

DA SILVA, I. G. Vigotski, Defectologia e Processo Educativo. Revista Pleiade, v. 9, n. 17, p. 77-82,2016.

MELLO, E. de F. F. de; TEIXEIRA, A. C. A interação social descrita por Vigotski e a sua possível ligação com a aprendizagem colaborativa através das tecnologias em rede. In: IX Anped Sul - Seminário de Pesquisa em Educação da Região Sul. Anais do IX Anped Sul, Caxias do Sul: UCS, 2012, p. 01-15.

FACCI, M. G. D. A periodização do desenvolvimento psicológico individual na perspectiva de Leontiev, Elkonin e Vigotski. Cadernos Cedes, v. 24, n. 62, p. 64-81, 2004.

FRIGOTTO, G. Cidadania e formação técnico-profissional: desafios neste fim de século. In: SILVA, L. H. et al. (Org.). Novos mapas culturais, novas perspectivas educacionais. Porto Alegre: Sulina, 1996.

FROMM, E. O conceito marxista de homem. In: MARX, K. Manuscritos econômicos e filosóficos. Rio de Janeiro: Civilização Brasileira, 1962.

KRAMER, S. De que professor precisamos para a educação infantil? Uma pergunta, várias respostas. Pátio Educação Infantil. Ano 1, no 2. Ago/Nov 2003.

LEONTIEV, A. O homem e a cultura. O Desenvolvimento do Psiquismo. Ed. Horizonte Universitário, 1978. 
LESSA, S.; TONET, I. Proletariado e sujeito revolucionário. São Paulo: Instituto Lukács, 2012.

LOMBARDI, J.C. Educação e ensino em Marx e Engels. In: LUCENA, C.; SILVA JUNIOR, J. dos R. (Orgs). Trabalho e Educação no Século XXI: Experiências Internacionais. São Paulo: Xamã, 2012. p. 99-125.

MANACORDA, M.A. Marx e a pedagogia moderna. São Paulo: Cortez, 1996.

MARSIGLIA, A. C. G. A prática pedagógica histórico-crítica na educação infantil e ensino fundamental. Campinas: Autores Associados, 2011.

MARTINS, L. Da formação humana em Marx à crítica da pedagogia das competências. In: DUARTE, N. Crítica ao fetichismo da individualidade. São Paulo: Autores Associados, 2004

MARX, K. Manuscritos econômicos e filosóficos. Rio de Janeiro: Civilização Brasileira, 1962.

MARX, K.; ENGELS, F. Textos sobre Educação e Ensino. São Paulo: Centauro, 2004.

A ideologia alemã. São Paulo: Moraes, 1984.

MELLO, S. A. As práticas educativas e as conquistas de desenvolvimento das crianças pequenas. In: RODRIGUES, Elaine \& ROSIN, S. M. Infância e Práticas educativas. Maringá: Eduem, 2007a.

MELLO, S. A. FARIAS M. A. A escola como lugar da cultura mais elaborada. Educação Santa Maria, v. 35, n. 1, p. 53-68, jan/abr. 2010.

MELLO, S.A. LUGLE, A. M. C. Formação de professores: Implicações pedagógicas da Teoria Histórico-Cultural. Revista Contrapontos, v. 14, n. 2, p. 259-274, 2014.

Infância e humanização: algumas considerações na perspectiva histórico-cultural. Perspectiva: Florianópolis, v. 25, n. 1, 83-104, jan/jun, 2007b.

MORUZZI, A. B. Linguagens, interações e brincadeiras - preposições para o currículo na educação infantil. Revista Educação e Linguagens, v. 3, n. 5, 2014.

NETTO, M. B.; LUCENA, C. A Luta pela Instrução Pública na obra de Marx e Engels. In: OMENA, A et al. Trabalho, Estado e Educação: considerações teóricas. Uberlândia: Navegando publicações, 2016. p. 55-82.

NOGUEIRA, A. A. et al. Interações e desenvolvimento da linguagem oral em crianças na creche: uma abordagem histórico-cultural. 2016. Tese (Doutorado em Educação) - Universidade Federal do Amazonas, Manaus, 2016.

PARANÁ. Orientações para (re)elaboração, implementação e avaliação de proposta pedagógica na educação infantil. Superintendência da Educação - Departamento de Ensino Fundamental. Coordenação Pedagógica de Educação Infantil. Curitiba,2006.

SAVIANI, D. Pedagogia histórico-crítica: primeiras aproximações. 7. ed. São Paulo: Autores Associados/Cortez, 2000.

VIGOTSKY, L. S.; COLE, M. A formação social da mente: o desenvolvimento dos processos psicológicos superiores. 6. ed. São Paulo: Martins Fontes, 1998.

\section{Notas}

${ }^{1}$ Nomenclatura elegida pelas autoras.

${ }^{2}$ Aqui, nos atentaremos a expor as fases correspondentes à faixa etária de 0 a 5 anos.

${ }^{3}$ Para mantermos os sigilos e a ética, os entrevistados serão identificados por letras, de A a H. 
* Mestranda em Educação pela Universidade Estadual de Londrina, Londrina, Paraná, Brasil.

** Professora doutora da Universidade Estadual de Londrina, Londrina, Paraná, Brasil.

\section{Correspondência}

Marta Silene Ferreira Barros - Universidade Estadual de Londrina, Centro de Educação Comunicação e Artes. Rodovia Celso Garcia Cid, Pr 445 Km 380, Cx. Postal 6001. Campus Universitário. CEP: 86051980.

Londrina, Paraná, Brasil.

E-mail: dayannevicentini@hotmail.com - mbarros_22@hotmail.com

Recebido em 26 de agosto de 2016

Aprovado em 05 de janeiro de 2017 